\title{
Scientific writing: a randomized controlled trial comparing standard and on-line instruction
}

\author{
Amruta Phadtare ${ }^{1}$, Anu Bahmani ${ }^{1}$, Anand Shah ${ }^{2}$ and Ricardo Pietrobon*3
}

\begin{abstract}
Address: ${ }^{1}$ Kalpavriksha Healthcare and Research, 301/A-wing, Saikrupa, Next to Ganesh Chhhaya, Anandnagar, Din Dayal Road, Dombivli West, Thane, 421202, Maharashtra, India, 2University of Pennsylvania, Philadelphia and Duke University Medical Center, DUMC Box 3094, Durham, NC, 27710, USA and ${ }^{3}$ Research on Research, Duke University Health System and Duke NUS Graduate Medical School in Singapore, DUMC Box 3094, Durham, NC 27710, USA
\end{abstract}

Email: Amruta Phadtare -dramruta@gmail.com; Anu Bahmani - kalpavrikshha@gmail.com; Anand Shah - anand.shah@alumni.duke.edu; Ricardo Pietrobon* - rpietro@duke.edu

* Corresponding author

Published: 27 May 2009

BMC Medical Education 2009, 9:27 doi:10.1186/1472-6920-9-27
Received: 9 July 2008

Accepted: 27 May 2009

This article is available from: http://www.biomedcentral.com/1472-6920/9/27

(c) 2009 Phadtare et al; licensee BioMed Central Ltd.

This is an Open Access article distributed under the terms of the Creative Commons Attribution License (http://creativecommons.org/licenses/by/2.0), which permits unrestricted use, distribution, and reproduction in any medium, provided the original work is properly cited.

\begin{abstract}
Background: Writing plays a central role in the communication of scientific ideas and is therefore a key aspect in researcher education, ultimately determining the success and long-term sustainability of their careers. Despite the growing popularity of e-learning, we are not aware of any existing study comparing on-line vs. traditional classroom-based methods for teaching scientific writing.

Methods: Forty eight participants from a medical, nursing and physiotherapy background from US and Brazil were randomly assigned to two groups $(n=24$ per group): An on-line writing workshop group (on-line group), in which participants used virtual communication, google docs and standard writing templates, and a standard writing guidance training (standard group) where participants received standard instruction without the aid of virtual communication and writing templates. Two outcomes, manuscript quality was assessed using the scores obtained in Six subgroup analysis scale as the primary outcome measure, and satisfaction scores with Likert scale were evaluated. To control for observer variability, inter-observer reliability was assessed using Fleiss's kappa. A posthoc analysis comparing rates of communication between mentors and participants was performed. Nonparametric tests were used to assess intervention efficacy.
\end{abstract}

Results: Excellent inter-observer reliability among three reviewers was found, with an Intraclass Correlation Coefficient (ICC) agreement $=0.931882$ and ICC consistency $=0.932485$. On-line group had better overall manuscript quality $(p=0.0017$, SSQSavg score $75.3 \pm 14.21$, ranging from 37 to 94$)$ compared to the standard group ( $47.27 \pm 14.64$, ranging from 20 to 72$)$. Participant satisfaction was higher in the on-line group $(4.3 \pm 0.73)$ compared to the standard group ( $3.09 \pm$ I.II) $(p=0.00 \mathrm{I})$. The standard group also had fewer communication events compared to the online group $(0.91 \pm 0.81$ vs. $2.05 \pm 1.23 ; p=0.0219)$.

Conclusion: Our protocol for on-line scientific writing instruction is better than standard face-toface instruction in terms of writing quality and student satisfaction. Future studies should evaluate the protocol efficacy in larger longitudinal cohorts involving participants from different languages. 


\section{Background}

Scientific writing is the primary way used by researchers to communicate their findings and project ideas to peers and the general public. Essential for determining their career progress and sustainability, researchers might fail in situations where their science is good but not communicated in a clear and persuasive manner. [1-4] Although multiple previous studies have compared on-line and traditional training methodologies, [5-10] we are not aware of previous studies comparing different methodologies to the training of researchers in scientific writing.

Traditional methods of instruction such as classroom training, seminars and workshops, are inherently inflexible in terms of scheduling, location and customizability. Moreover, they are often perceived as outdated, boring, impersonal, and inapplicable to the real-world demands of the workplace. [11-15] Writing in collaboration tends to be superior to writing in isolation, as individual strengths are pooled and deficiencies improved, [16] having also been shown to increase publication rates among faculty members.[17] Although shared collegial authority is a feature of collaborative writing, [18] geographically dispersed teams face significant barriers related to dissent on content, hostility within the group and disagreement on strategy.[5] In addition, divergent backgrounds, asynchronous feedback, and communication issues all can affect a group's progress.[6]

The need for new instructional tools and techniques to overcome these limitations [19] has resulted in the rise of distance learning, e-learning, and virtual simulation. Distance education is promising since it is independent of time and place, reducing dissemination costs, multiplying learning opportunities, and eliminating travel time and related expenses. [19] For example, rather than having to follow a rigid class schedule, distance learners can receive course materials at home, enabling them to review materials and complete assignments with greater flexibility. Distance education is most useful when students and teachers are physically separated, requiring a technologydependent interface.[19] As an extension of distance education, e-learning involves the delivery of course materials and the completion of assignments via the internet, frequently using streaming media (audio/video), live Webcasts, hyperlinked data and various other communication tools such as chat rooms, instant messaging, and videoconferencing.[20] A recent comparison of Web-based and face-to-face graduate curricula favored the Web-based course in terms of lower dropout rates and increased flexibility, affordability and attractiveness to students.[9] In addition, this evolving methodology allows for time/ space flexibility, [21] wide accessibility, frequent contact among students and teachers, [7] and individual customization. [22] Potentially improving interaction, collabora- tion and feedback. Despite its advantages, Web-based learning has drawbacks, including feelings of isolation, frustration with unfamiliar practices, $[8,20]$ lack of necessary infrastructure, and new costs associated with on-line courses.

Despite the paucity of evidence supporting its effectiveness in scientific writing instruction, a substantial increase in e-learning seems inevitable. It is therefore imperative to compare its efficacy with traditional instruction. This may ultimately contribute to the improvement of e-learning methods. Previous studies have compared Web-based and traditional classroom instruction. However, these studies have focused exclusively on student performance, $[22,23]$ internet-based degree and certificate programs, [24] reactions of college staff to surveys, [25] and student grades.[26] They have also been applied narrowly to graduate-level courses in learning disabilities.[10] These studies did not address the specific issues surrounding on-line scientific writing instruction.

Our study used a randomized controlled trial design to compare on-line and traditional methods of instruction for training novice researchers in scientific writing. Outcomes included measurements of text quality, participantmentor communication events and participant satisfaction.

\section{Methods \\ Participants}

Participants were recruited from second and third year programs in medical, nursing and physiotherapy schools in the United States and Brazil, all receiving informed consent prior to the initiation of study activities. The study was approved by the Institutional Review Board at Duke University and conducted between 2005 and 2007.

\section{Inclusion criteria}

We recruited novice researchers with minimal previous scientific writing experience and no previous publications in Medline indexed journals. All eligible participants were enrolled, with no further exclusion criteria.

\section{Sample Size}

Based on a pilot study of nine medical students writing manuscripts with our research group http://www.resear chonresearch.org, we estimated a standard deviation of 15 points in the SSQS. Assuming a 20\% difference between groups, the minimum sample size was estimated to be 22 participants per group, or 44 in all. To allow for attrition, our final sample size was set at 48 .

\section{Randomization, Sequence Generation and Concealment} Random numbers were generated with GNU-R http:// www.r-project.org/, using a 1:1 proportion, blocks of 
eight individuals, and stratification based on program of origin (nursing, physical therapy, and medicine). An initial randomization schedule was generated for 48 participants, followed by a sequence of size 15 to account for dropouts. Group assignments were placed in sealed envelopes and revealed after participants had signed informed consent. To ensure bliding, assignments were disclosed to analysts only after the results had been delivered. After stratified randomization, half of the pairs were assigned to the standard instruction course, while the other half were assigned to the on-line group.

\section{Interventions \& Implementation}

Participants were randomly assigned to one of two settings: standard writing guidance and an on-line writing workshop.

\section{On-line writing workshop group}

In this group, the primary tools of instruction were PowerPoint presentations and audio conferences, supplemented by email, Google Docs and writing templates. Instructions for installing software, using Voice Over the Internet Protocol (VoIP) applications http:// www.skype.com/ and working with manuscript templates http://www.researchonresearch.org/?q=node/14 were provided via email and PowerPoint presentations. Participants wrote their manuscripts using the Web-based word processor Writely (now Google Docs - http:// docs.google.com/), and used VoIP applications, instant messaging and email to communicate with their mentors. After an initial session of instruction, mentors contacted students twice a week by email, with virtual meetings scheduled as needed. Students used customized writing templates, populating their manuscripts section by section in pre structured layouts. Templates were available on-line for reference. Google Docs, an open-access, Webbased word processor that enables collaboration among any number of researchers, anywhere in the world, was used to write, review, edit and share manuscripts. This application allows for synchronous as well as ashynchronous collaborative writing, allowing multiple users to edit the same source document, with a user-friendly interface. It archives previous versions along with details of the revision history, which allows users to compare versions of a document in different stages of editing. The on-line writing workshop group procedure is diagrammed in Figure 1.

\section{Standard writing guidance group}

In this group, topics were assigned in a classroom setting. Participants could ask questions at the time of assignment, and they could communicate with instructors by email or conference call when necessary. Mentors, accessible by appointment, were assigned to each pair of participants. Together with their mentors they selected topics of mutual interest, sometimes complying with existing course requirements. Participants worked independently, using concepts and materials presented in class and consulting mentors by telephone. They used standard, computer-based word processing software such as Microsoft Word http://www.microsoft.com/office/ or Open Office http://www.openoffice.org/ to write their papers.

Mentor allocation, research question assignment and manuscript writing were executed in the same manner in both groups. In both groups, pairs of participants worked together to complete either the Introduction or Discussion section of a manuscript. On-line course materials were in English, while mentor support was provided in English and Portuguese.

\section{Outcomes and assessment strategies}

Outcome variables consisted of manuscript quality and self-reported participant satisfaction. The quality of each manuscript was evaluated according to well-defined parameters using the Six-Subgroup Quality Scale (SSQS). [27] [see Additional file 1]. These parameters assessed the manuscripts' structure, application of research principles, and sequential flow of information. For manuscripts written in Portuguese, a bilingual researcher (RP) ensured that evaluations were cross-culturally consistent. Self-reported satisfaction with the overall training experience was measured using the Likert scale, with participants responding to statements on a scale of strongly disagreeing to strongly agreeing. Post hoc analysis evaluated the number of communication events (emails or phone calls) between participants and mentors. Evaluations were performed by three different reviewers. To ensure unbiased findings, statistical analysis was blinded; with analysts being unaware of which group participants were assigned to until the study analysis was complete.

\section{Quality of scientific writing}

Manuscripts were analyzed by three expert reviewers: a nurse, a research technician, and a clinical epidemiologist. Prior to the study, reviewers participated in a preliminary session in which they rated ten examples of Introduction and Discussion sections using the SSQS scale. The scale included criteria such as focus; logical connection among portions of text; choice and arrangement of words (readable vs. awkward); writing mechanics (usage, grammar, spelling); content (engaged vs. uninvolved, acknowledgment of alternative points of view vs. single-mindedness); clarity of purpose and appropriateness of tone for the intended audience (clear vs. unclear purpose, language and tone appropriate and consistent); organization and development (support and elaboration, completeness, correct use of paragraphs); and style (sentence structure, concision, daring vs. safe). Disagreements were resolved by consensus. All criteria were graded on a scale of 1 to 5 . 


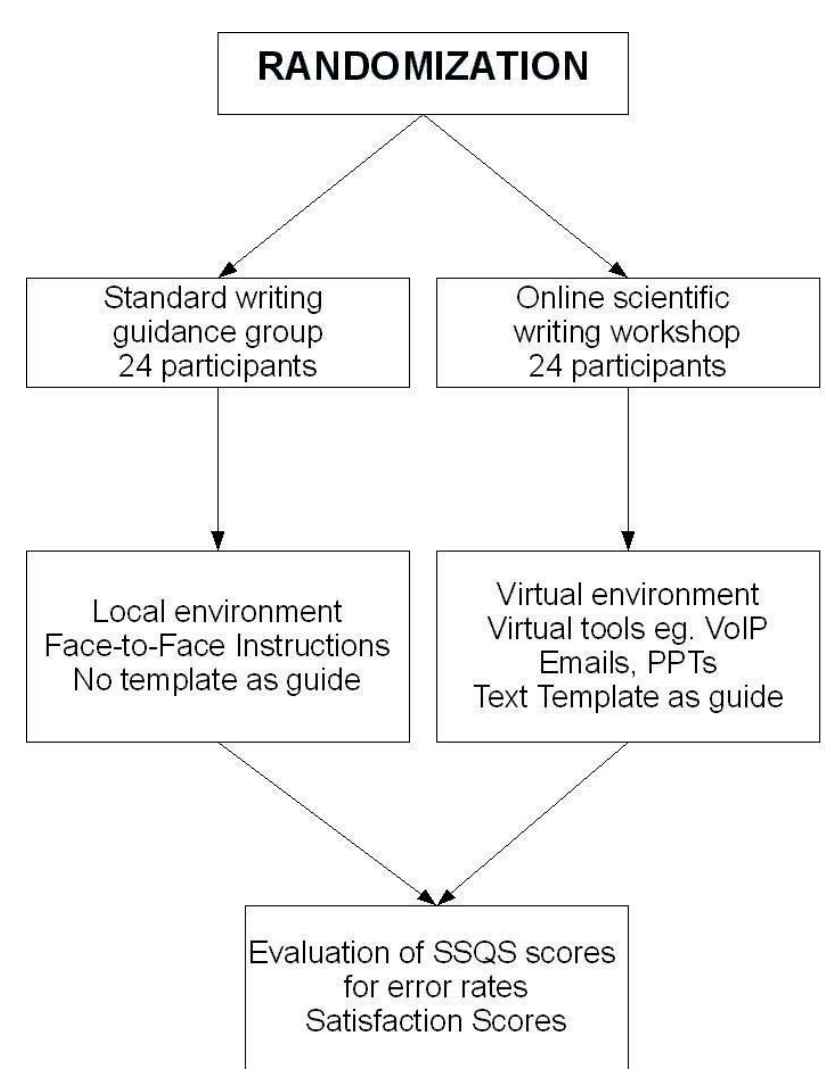

Figure I

Diagrammatic representation of the method implementation.

\section{Satisfaction scores}

Self-reported satisfaction was measured using a 5-point Likert scale, participants responding to statements concerning their satisfaction with the course on a scale from "strongly disagree" to "strongly agree" ( 1 = Strongly disagree, 2 = Disagree, 3 = Neither agree nor disagree, $4=$ Agree, 5 = Strongly Agree).

\section{Communication events}

Communication events were defined as any interactions between participants and mentors, by email or phone, for the purpose of discussing manuscripts and receiving feedback. This outcome was considered secondary.

\section{Qualitative study}

Using a convenience sampling method, we enrolled a subset of 16 novice researchers in a parallel qualitative study designed to identify the challenges encountered by participants in writing scientific manuscripts. They reported their progress using a prescribed methodology, described the problems they encountered, and identified their areas of greatest and least competence. Focus group discussions were transcribed using conventional qualitative analysis techniques. The results of this study have been reported elsewhere. [28]

\section{Covariates}

Potential confounding factors included age, gender, marital status, course of study, previous experience with scientific writing, and choice of writing section (Introduction or Discussion).

\section{Statistical Methods}

Calculations were performed using means and standard deviations for continuous variables, and frequencies and percentages for categorical variables. Efficacy was measured by analyzing the variance of SSSQ and satisfaction scores. SSQS scores were normalized from 0 to 100. An intention-to-treat protocol was preserved. We did not prevent students from employing other methods to improve their writing. Inter-observer reliability was assessed using Fleiss's kappa, then the two groups were compared by way of non-parametric tests for each domain of the SSQS scales using Intercooled Stata. Analysis was performed with GNU-R. A combination of kappa statistics was used to measure inter-observer reliability. This was followed by non-parametric tests comparing the groups' scores.

\section{Results \\ Participant Flow}

63 participants were initially enrolled after signing informed consent, of which 15 dropped out before randomization due to time constraints. The remaining 48 were randomly assigned to two groups of 24 each.

\section{Recruitment}

Participants were recruited between September 2005 and July 2006, with follow-up ending in November 2007.

\section{Baseline data}

There were no statistically significant differences between groups with respect to age, gender, marital status, course of study, choice of writing section or previous experience (Table 1). Participants were balanced regarding gender distribution, mostly single, and with no previous experience writing scientific manuscripts. Most participants used the Introduction as the section used for participation in this study.

\section{Outcomes and Estimations}

Excellent inter-observer reliability was found among the three reviewers, with an Intraclass Correlation Coefficient of 0.93 . Writing quality measured by the average SSQS for the on-line group $(75.3 \pm 14.21$, ranging from 37 to 94$)$ was lower than that of the standard group $(47.27 \pm 14.64$, ranging from 20-72) ( $\mathrm{p}=0.0017)$, and participants in the on-line group were more satisfied with the experience $(4.3$ \pm 0.73 , ranging from 3 to 5 ) than their counterparts in the 
traditional group $(3.09 \pm 1.11$, ranging from 1 to 5$)(\mathrm{p}=$ $0.001)$.

Post hoc analysis revealed that participants in the traditional group reported fewer communication events $(0.91$ $\pm 0.81)$ than the on-line group $(2.05 \pm 1.23 ; \mathrm{p}=0.0219)$ (Table 2). Also, participants with previous experience in scientific writing made fewer errors than participants with no experience $(63.82 \pm 18.60$ vs. $59.48 \pm 20.78$ respectively; $\mathrm{p}=0.002)$. Reported satisfaction and quantity of communication were not significantly affected by previous experience. For all other variables, including as gender, marital status, course of study, choice of writing section and attitude toward the writing process, the two groups were comparable and there were no significant differences (Table 3).

\section{Discussion}

Our study found that the on-line scientific writing group performed significantly better than the standard writing guidance group in terms of writing quality, also reporting greater overall satisfaction. The on-line group also reported a greater number of participant-mentor communication events in the post hoc analysis. Because this was not the primary objective of this study, it should be investigated further to understand the effects of on-line learning on collaboration and group instruction. A significantly lower error rate occurred among participants with previous scientific writing experience, but reported satisfaction was unaffected by writing experience. Interobserver reliability for the results of this study was high. The use of Google Docs clearly enhanced participants' familiarity with an increasingly popular method of collaboration, as well as improving the mentors' efficiency.

Web-based education has become increasingly popular over the past decade. Multiple studies have evaluated the effectiveness of Web-based and other computer-assisted teaching methods. Although they have mainly addressed distance education, $[23,27,29]$ broad comparisons to this study are possible, as distance education often includes Web-based or other computer-assisted education. Significant advantages of on-line teaching methods over traditional classroom methods have been previously demonstrated, [28,30-33] on-line instruction producing enhanced performance, [30,34] cognitive gains and higher satisfaction, [32] and improved test scores. [31] For example, in one study [31] students who were provided with Web-based educational materials obtained higher scores than those who were not provided with similar materials. It has also been shown that computer environments are conducive to the presentation of visual material that tends to benefit students. [29,35,36] Nurses have shown a greater willingness to adopt Web-based methodologies, [37] and they consider the benefits to far outweigh their disadvantages. 48

Although studies favoring traditional teaching over online methods do exist, [23] studies yielding neutral results are more prevalent. A comparison of the two methods in graduate-level courses in learning disabilities and other curricula evaluated quality, test scores, cognitive gains, and student performance, success and satisfaction, finding no significant differences between distance education using on-line materials and traditional classroom-based

Table I: Baseline characteristics

\begin{tabular}{|c|c|c|c|}
\hline Baseline characteristics & $\begin{array}{l}\text { Mean(Standard Deviation) } \\
\text { [Range Values] } \\
\text { on-line scientific writing workshop }\end{array}$ & Standard writing guidance & $P$ value \\
\hline Age & $23.54(+/-1.50)[9,10,23,27,29,30]$ & $23.17(+/-1.55)[9,10,23,27,29,30]$ & 0.9248 \\
\hline Gender & & & 0.6892 \\
\hline Female & $13 / 48(27.08 \%)$ & $14 / 48(29.17 \%)$ & \\
\hline Male & $1 \mathrm{l} / 48(22.92 \%)$ & $10 / 48(20.83 \%)$ & \\
\hline Marital status & & & 0.4701 \\
\hline Married & $\mathrm{I} / 48(2.08 \%)$ & $\mathrm{I} / 48(2.08 \%)$ & \\
\hline Single & $23 / 48(47.92 \%)$ & 23/48(47.92\%) & \\
\hline Course & & & 0.768 \\
\hline Med & 13/48(27.83\%) & $14 / 48(29.16 \%)$ & \\
\hline Nursing & $6 / 48(12.5 \%)$ & $5 / 48(10.42 \%)$ & \\
\hline PT & $5 / 48(10.42 \%)$ & $4 / 48(8.33 \%)$ & \\
\hline Previous experience research writing & & & 0.574 \\
\hline No & $16 / 48(33.33 \%)$ & $18 / 48(37.5 \%)$ & \\
\hline Yes & $8 / 48(16.66 \%)$ & $5 / 48(10.42 \%)$ & \\
\hline \multicolumn{4}{|l|}{ Manuscript section } \\
\hline Introduction & $16 / 48(33 \%)$ & I3/48 (27\%) & 0.685 \\
\hline Discussion & I I/48 (22.0\%) & $8 / 48(16.6 \%)$ & 0.544 \\
\hline
\end{tabular}


instruction. $[10,22,26,38]$ Since on-line learning is becoming increasingly prevalent due to its easy scalability and flexibility in scheduling, even despite its current drawbacks, on-line teaching methods will likely improve with the emergence of new Web-based technologies and thus need constant re-evaluation.

Student satisfaction is an important consideration when implementing new teaching methods and the present study finds greater satisfaction with on-line workshops. Carr, [39] however, found that student satisfaction was lower in Web-based distance education despite higher rates of success. The author attributed this result to technical difficulties, including problems with internet connection and computer problems requiring the assistance of engineers, which ultimately resulted in greater time expenditure by students in the distance learning environment. Finally, on-line courses can also automate processes such as test score collation, saving time by reducing faculty workload and thus providing students with faster feedback. [40]

Student-mentor communication was higher in the Webbased group, indicating a more open atmosphere for comments and criticism. Earlier studies evaluating students' reactions toward distance education have documented feelings of loneliness and frustration, and have cautioned against a shift away from traditional modes of group learning. [41] However, this trend is likely to change as students that have grown up surrounded by Web applications as part of their life enter distance learning programs. These students are more likely to offer critical suggestions, facilitating beneficial changes to the curriculum. [42,43]

Mixed results for performance advantages and decision making have been noted on a variety of tasks in computer mediated versus face-to-face learning environments. [44] Contributors to these mixed results included factors such as participants' prior experience with on-line courses, their grades, [34,37] computer competency, [45] and idiosyncratic interactions with a given system of instruction as well as instructor skills, [46] the presence or absence of supervision, [47] and the relatively slow diffusion of Web- based technology as described by Karl Pajo and Catherine Wallace. [25] Web-based learning is a maturing technology, and early studies may have suffered from poor program design and students' lack of familiarity with on-line environments, as shown in a study by Spooner. [29] This study analyzed student response to the two types of instruction, and, interestingly, results for one parameter (class organization) were contradictory: Traditional methods were rated superior in one of the two courses studied, while distance education was favored in the other.

The use of Blackboard ${ }^{\mathrm{TM}}$ http://www.blackboard.com/, a Web-based learning system, has been proven effective in helping students write research papers. [48] However, in this system, access is limited to registered candidates or institutions, preventing collaboration with outside researchers who might be working on the same project. Also, while the system is useful for tracking students' use of course materials and monitoring their progress, it is not open-source and can be costly to implement. The present study used Google Docs http://docs.google.com/, which is a freely available interface for sharing, editing, and tracking on-line documents. We are not aware of any existing previous study making use of Google Docs for the purposes of scientific writing. Scientific writing demands collaboration, in the form of back-and-forth communication with collaborators, peers, mentors and outside researchers. Given this requirement, Google Docs is an excellent solution that precludes the time-consuming compiling of multiple iterations of text that occurs with the exchange of documents via email or hard copies.

Despite significant advances in relation to the previous literature in the field, our study has limitations. First, the number of potential confounding factors we could track was limited, and did not include subjects' prior participation in on-line courses, their grades, [34,37] proficiency with computers, [45] and interaction with the system of instruction, as well as instructor skills [46] and the presence or absence of supervision. [47] Examining these factors was beyond the scope of this study. Second, our mentors were not blinded, which may have resulted in bias. Because it was not possible to maintain blinding in

Table 2: Association between the two groups and the outcomes

\begin{tabular}{|c|c|c|c|}
\hline & $\begin{array}{l}\text { Mean } \\
\text { (Standard Deviation) } \\
\text { [Range Values] }\end{array}$ & $\begin{array}{l}\text { Mean } \\
\text { (Standard Deviation) } \\
\text { [Range Values] }\end{array}$ & \\
\hline Outcome & on-line scientific writing workshop & Standard writing guidance & $P$ value \\
\hline SSQSavg & $75.3(+/-14.21)[37-94]$ & $47.27(+/-14.64)[20-72]$ & 0.0017 \\
\hline Satisfaction with method & $4.3(+/-0.73)[3-5]$ & $3.09(+/-1.11)[1-5]$ & $<0.001$ \\
\hline Number communication events with mentor & $2.05(+/-1.23)[1-6]$ & $0.91(+/-0.81)[0-3]$ & 0.0219 \\
\hline
\end{tabular}


Table 3: Post hoc analysis of outcomes and other variables

\begin{tabular}{|c|c|c|c|c|c|}
\hline \multirow[b]{2}{*}{ Predictors } & \multirow[b]{2}{*}{ P-values } & \multicolumn{2}{|c|}{ Number communication events } & \multicolumn{2}{|c|}{ Satisfaction } \\
\hline & & $\begin{array}{l}\text { Mean } \\
\text { (Standard Deviation) } \\
\text { Range Values }\end{array}$ & P-values & $\begin{array}{l}\text { Mean } \\
\text { (Standard Deviation) } \\
\text { Range Values }\end{array}$ & P-values \\
\hline Enjoys writing & 0.5881 & & 0.972 & & 0.8264 \\
\hline 1 & & $1+/-(1) 0-2$ & & $2.67+/-(I .52) I-4$ & \\
\hline 2 & & $1.14+/-(0.69) 0-2$ & & $3.7 I+/-(1.49) I-5$ & \\
\hline 3 & & $1.94+/-(1.43) 0-6$ & & $3.82+/-(0.95) 0-2$ & \\
\hline 4 & & $1.08+/-(0.99) 0-3$ & & $3.67+/-(0.98) 2-5$ & \\
\hline 5 & & $1.33+/-(0.57) \mathrm{I}-2$ & & $3.67+/-(1.52) 2-5$ & \\
\hline Gender & 0.1028 & & 0.3819 & & 0.8127 \\
\hline Female & & $1.52+/-(1.32) 0-6$ & & $3.6+/-(I .22) I-5$ & \\
\hline Male & & $1.35+/-(0.93) 0-4$ & & $3.76+/-(0.97) 2-5$ & \\
\hline Marital status & 0.289 & & 0.9655 & & 0.7156 \\
\hline Married & & $1.5+/-(0.70) \mathrm{I}-2$ & & $44-4$ & \\
\hline Single & & $1.45+/-(1.19) 0-6$ & & $3.65+/-(1.14) \mathrm{I}-5$ & \\
\hline Course & 0.5727 & & 0.4723 & & 0.05372 \\
\hline Med & & $1.44+/-(1.04) 0-4$ & & $3.4+/-(1.08) 1-5$ & \\
\hline Nursing & & $1.87+/-(1.88) 0-6$ & & $4.25+/-(0.70) 3-5$ & \\
\hline PT & & $1.11+/-(0.60) 0-2$ & & $3.89+/-(1.36) \mathrm{I}-5$ & \\
\hline Previous experience research writing & 0.002 & & 0.1046 & & 0.3920 \\
\hline No & & $1.29+/-(1.00) 0-4$ & & $3.6 \mathrm{I}+/-(1.05) \mathrm{I}-5$ & \\
\hline Yes & & $1.91+/-(1.5 I) 0-6$ & & $3.82+/-(1.32) \mathrm{I}-5$ & \\
\hline
\end{tabular}

the study's early stages, we ensured that the final statistical analysis was blinded for an unbiased interpretation of the results. Third, our study did not evaluate participants' perceptions of their own performance. Several earlier studies have demonstrated that, although the two methods are comparable in terms of performance, [[9,36,42,43], and [49]] the same consistency is not seen in the participants' perceptions of their own performance. [50-52] While the present study did not include a parameter for self-assessment, reports of satisfaction provide a rough correspondence. Last, our current study used the SSQS scale for measuring manuscript quality without this scale having a formal cross-cultural validation. As we did not have a large enough sample to conduct a stratified analysis, it is unclear whether language might have affected our outcomes.

Future studies should address the problems associated with using imperfect measurement scales such as SSQS, which is prone to subjective bias, and tools should be developed to objectively measure writing quality. The lack of tools to objectively evaluate manuscript quality and participants' self-assessment makes it difficult to interpret the results of this type of study. Thus, developing tools that consistently evaluate participants' perceptions of their own performance, as well as objective measurements of the quality of scientific writing, could prove beneficial. Several other factors are also found to influence the outcome of this type of study, including participants' previ- ous experience with on-line courses, their grades, [34,37] computer competency, [45] and interaction with the system in question, as well as instructor skill [46] and the presence or absence of supervision. [47] Future studies should enroll participants in sufficient numbers to stratify comparison groups according to these factors.

\section{Conclusion}

This study suggests that the on-line scientific writing methodology was superior to traditional classroom-based instruction, which suggests that reservations concerning Web-based instruction should be reconsidered. Webbased workshops also resulted in reports of greater satisfaction among participants, although the generalization of this result should be tested in future studies. We therefore strongly encourage the use of on-line environment to provide a highly scalable method to educate the next generation of biomedical research.

\section{Competing interests}

The authors declare that they have no competing interests.

\section{Authors' contributions}

AP-participated in manuscript writing and critical analysis of results. AB-participated in manuscript writing and critical analysis. AS-performed data analysis, participated in study design and manuscript review. RP-designed and conducted the study and reviewed the manuscript. All authors read and approved the final manuscript. 


\section{Additional material}

\section{Additional file 1}

Six Sub Group Quality Scale. This scale provided was used to assess manuscript quality, which was a primary outcome.

Click here for file

[http://www.biomedcentral.com/content/supplementary/14726920-9-27-S1.doc]

\section{Acknowledgements}

This publication was made possible by

I. Grant Number I ULI RR024 I28-0 I from the National Center for Research Resources (NCRR), a component of the National Institutes of Health (NIH), and NIH Roadmap for Medical Research. Its contents are solely the responsibility of the authors and do not necessarily represent the official view of NCRR or NIH. Information on NCRR is available at http:// www.ncrr.nih.govl. Information on Re-engineering the Clinical Research Enterprise can be obtained from http://nihroadmap.nih.gov/clinicalresearch/ overview-translational.asp

2. DU CIT Scientific Writing Workshop using On-line Instructional Technology, Surgery, School of Nursing, Physical and Occupational Therapy, Community and Family Medicine.

\section{References}

I. Peh WCG: Scientific writing and publishing: its importance to radiologists. Biomed Imaging Interv J 2007, 3:e55.

2. Rothman K: Writing for epidemiology. Epidemiology 1998, 9:333-7.

3. David AS: How to do it: write a classic paper. BMJ 1990, 300:30-3I.

4. Day R, Gastel B: How to write and publish a scientific paper. 6th edition. Westport, CT: Greenwood Press; 2006.

5. Hinds PJ, Bailey DE: Out of sight, out of sync: Understanding conflict in distributed teams. Organization Science 2003, I 4(6):6|5-632.

6. Gennari JH, Weng C, Benedetti J, McDonald DW: Asynchronous communication among clinical researchers: A study for systems design. Int J Med Inform 2005, 74(I 0):797-807.

7. Cole RA: Issues in Web-based pedagogy: A critical primer. Westport, CT: Greenwood Press; 2000.

8. Cook D: Web-based learning: pros, cons and controversies. Clin Med 2007, 7:37-42.

9. Horiuchi S, Yukari Y, Miki K, Yumi S, Kazuhiro N: Evaluation of a Web-based graduate continuing nursing education program in Japan: A randomized controlled trial. Nurse Education Today 2008, 29(2): 140- I 49.

10. Tinnerman L: A Comparative Study Between Traditional and Distance Education Instructional Environments Involving Two Graduate Level Learning Disabilities Classes. International Journal of Instructional Technology and Learning 2006, 3(3): I-64.

1I. Diamond R: Broad curriculum reform is needed if students are to master core skills. Chronicle of Higher Education 1997 43(47): B7

12. Gardiner LF: Producing dramatic increases in student learning: Can we do it? National Teaching and Learning Forum 1997 6(2):8-10.

13. Charles H: A proper education. Change 1998, 30:12-19.

14. Roueche JE: American Imperative-Essay, Virtual Library". 1998.

15. Wingspread Group on Higher Education: An American Imperative: Higher Expectations for Higher Education. Racine, Wl: The Johnson Foundation, Inc; 1993.

16. Group work and collaborative writing [http://dhc.ucdavis.edu/ vohs/secll.html]
17. Grzybowski SCW, Bates J, Calam B, Alred J, Martin RE, Andrew R, Rieb L, Harris S, Wiebe C, Knell E, Berger S: A physician peer support writing group. FamMed 2003, 35(3): 195-20I.

18. Galligan L, Cretchley P, George L, Martin McDonald K, McDonald J Rankin J: Evolution and emerging trends of university writing groups. Queensland Journal of Educational Research 2003, 19(I):28-4I.

19. Glenn AS: A Comparison of Distance Learning and Traditional Learning Environments. 200I [http://www.eric.ed.goERICWebPortal/custom/portlets/recordDetails/detailm ini.jsp? nfpb=true\& \&ERICExtSearch SearchValue 0=ED457778\&E RICExtSearch SearchType 0=no\&accno=ED457778].

20. McKimm J, Jollie C, Cantillon P: ABC of learning and teaching: Web based learning. BMJ 2003, 326:870-873.

21. Takiya S, Archbold J, Berge ZL: Flexible training's intrusion on work/life balance. Turkish on-line Journal of Distance Education 2005, 6(2): [http://tojde.anadolu.edu.tr/tojde /8/articles/article5.htm].

22. Mehlenbacher B, Miller CR, Covington D, Larsen JS: Active and interactive learning on-line: a comparison of Web-based and conventional writing classes. Professional Communication, IEEE Transactions 2000, 43:166-184.

23. Sawyer T: The effects of computerized and conventional study guides on achievement in college students. Journal of Computer-Based Instruction 1998, I 5(3):80-8.

24. Wallace DR, Mutooni P: A comparative evaluation of World Wide Web-based and classroom teaching. J Eng Educ 1997, 86(3):2II-2I9.

25. Pajo K, Wallace C: Barriers to the uptake of Web-based technology by university teachers. Journal of Distance Education/Revue de l'enseignement à distance 200I, I 6(I):70-84.

26. Roach V, Lemasters L: Satisfaction with on-line learning: A comparative descriptive study. Journal of Interactive on-line Learning 2006, 5(3):317-332.

27. Ransdell S, Levy CM: Working memory constraints on writing quality and fluency. In The science of writing Edited by: Levy CM, Ransdell S. Mahwah: Lawrence Erlbaum Associates; 1996:93-105.

28. Shah J, Shah A, Pietrobon R: Scientific writing of novice researchers: what difficulties and encouragements do they encounter. Academic medicine: Journal of the Association of American Medical Colleges 2009, 84(4):5II-6.

29. Spooner F, Jordan L, Algozzine B, Spooner M: Student ratings of instruction in distance learning and on-campus classes. Journal of Educational Research 1999, 92: 132-40.

30. Smeaton $A$, Keogh $G$ : An analysis of the use of virtual delivery of undergraduate lectures. Computers and Education 1999 , 32(I):83-94.

31. Ochoa J: Randomized Comparison Between Traditional and Traditional Plus Interactive Web-Based Methods for Teaching Seizure Disorders. Teach Learn Med 2008, 20(2): I I4-I I7.

32. Jeffries P: Computer versus lecture: $A$ comparison of two methods of teaching oral medication administration in a nursing skills laboratory. Journal of Nursing Education 200I, 40(7):323-29.

33. Griffin J: Technology in the teaching of Neuroscience: enhanced students learning. ADV PHYSIOL EDUC 2003, 27:146-155.

34. Dutton J: Characteristics and Performance of Students in an on-line Section of Business Statistics. Journal of Statistics Education 2005, I3(3): [http://www.amstat.org/publications/jse/v/3n3/dut ton.html].

35. Pietrobon R, Guller U, Martins $H$, Menezes AP, Higgins LD, Jacobs DO: A suite of Web applications to streamline the interdisciplinary collaboration in secondary data analyses. BMC Medical Research Methodology 2004, 4(I):29.

36. Welsh J, Null C: The effects of computer-based instruction on college students' comprehension of classic research. Behavior Research Methods, Instruments and Computers 1991, 23:30I-305.

37. Huckstadt A: Evaluation of interactive on-line courses for advanced practice nurses. J Am Acad Nurse Pract 2005, I7(3):85-9.

38. Schoech $D$, Helton $D$ : Qualitative and quantitative analysis of a course taught via classroom and internet chatroom. Qualitative Soc Work 2002, I: I I I-124.

39. Sarah C: on-line psychology instruction is effective, but not satisfying, study finds. The Chronicle of Higher Education 2000, 46(27):A48. 
40. Anderson H: On-line Student Course Evaluations: Review of Literature and a Pilot Study. American Journal of Pharmaceutical Education 2005, 69(I): [http://www.ajpe.org].

4I. Hara N, Kling R: Student's frustrations with a Web-based distance education course. First Monday 1999, 4(12): [http:// www.firstmonday.org/issues/issue4 12/hara/index.html].

42. Layne $\mathrm{BH}$, DeCristofor JR, McGinty $\mathrm{D}$ : Electronic versus traditional student ratings of instruction. Res Higher Educ 1999, 40:22I-32.

43. Kasiar JB, Schroeder SL, Holstad SG: Comparison of traditional and Web-based course evaluation processes in a required, team-taught pharmacotherapy course. Am J Pharm Educ 200I, 63:268-70

44. Luppicini R: Review of computer mediated communication research for education. Instructional Science 2007, 35(2): |4|-|85.

45. Wojciechowski A: Individual Student Characteristics: Can Any Be Predictors Of Success In on-line Classes? Journal of Distance Learning Administration 2005, VIII(II): [http://www.westga.edu/ dis tance/ojdla/summer82/wojciechowski82.htm]

46. Wellman G: Comparing Learning Style to Performance in OnLine Teaching: Impact of Proctored vs. Un-Proctored Testing. Journal of Interactive on-line Learning 2005, 4(I):20-39.

47. Meyer K: Face-to-Face versus threaded discussions:The role of time and higher order thinking. JALN 2003, 7(3):55-65.

48. Stone V: Delivery of Web-based instruction using Blackboard: a collaborative project. I Med Libr Assoc 2004, 92(3):375-77.

49. Russell T: The No Significant Difference Phenomenon. 1999 [http://www.nosignificantdifference.org/]. North Carolina State University, Raleigh, NC, USA

50. Schoech D: Teaching over the Internet: Results of one doctoral course. Research on Social Work Practice 2000, I 0:467-487.

5I. Sonner BS: Success in the capstone business course - Assessing the effectiveness of distance learning. Journal of Education for Business 1999, 74:243-247.

52. Bower B: Distance education: Facing the faculty challenge. Journal of Distance Learning Administration 2001, 4(2): [http:// www.westga.edu/ distance/ojdla/summer42/bower42.html].

\section{Pre-publication history}

The pre-publication history for this paper can be accessed here:

http://www.biomedcentral.com/1472-6920/9/27/prepub
Publish with Biomed Central and every scientist can read your work free of charge

"BioMed Central will be the most significant development for disseminating the results of biomedical research in our lifetime. "

Sir Paul Nurse, Cancer Research UK

Your research papers will be:

- available free of charge to the entire biomedical community

- peer reviewed and published immediately upon acceptance

- cited in PubMed and archived on PubMed Central

- yours - you keep the copyright
BioMedcentral 